\title{
Missing men, missing infertility: The enactment of sex/gender in surveys in low- and middle-income countries
}

\author{
Jasmine Fledderjohann^, Celia Roberts
}

\begin{abstract}
Although reproduction involves (at least) two sexed bodies, men are often missing from in/ fertility research. Surveys such as the widely-used Demographic and Health Surveys (DHS) engage in often unintentional yet highly consequential practices of gendering. Here we identify two processes through which surveys have the potential to render male infertility invisible: defining the population at risk of infertility in an exclusionary way; and designing survey instruments to select out some groups/issues. Compiling information about survey samples and inclusion criteria in the DHS, and combining this with a qualitative examination of instrument design, we identify areas of men's invisibility across time and place. While inclusion of men in DHS samples has increased over time, some men (e.g. single and divorced, transgender) remain missing in many survey settings. This is problematic from a reproductive justice perspective. Survey results, which both reflect and contribute to men's invisibility, are widely used as an evidence-base for family and population policies. Moreover, reproductive health services are only made available to those whose reproductive health needs are recognized; men's exclusion from the reproductive discourse contributes to the stratification of reproduction. Men's underrepresentation in in/fertility data also reinforces the notion that reproduction is a woman's domain, and so contributes to a system that places responsibility for reproduction on women. It is vital to explore how gender is enacted or 'done' in such research.
\end{abstract}

Keywords: Survey data; masculinity; gender; infertility; population policy; global health; invisibilization; survey design; reproduction; LMICs

DOI 10.1515/pophzn-2018-0003

Received: 11 September 2017; Accepted: 30 April 2018

\section{Introduction}

Infertility-the inability to conceive or sustain a pregnancy to live birth (WHO, 2015) -is associated with a range of consequences around the globe, including stigma, mental distress, relationship instability and disruption, intimate partner violence, refusal of burial rites and exposure to sexually transmitted infections (Fledderjohann, 2012, 2017; Hollos, Larsen, Obono, \& Whitehouse, 2009; Inhorn, 2002; Inhorn \& van Balen, 2002; Rouchou, 2013; Stellar, Garcia-Moreno, Temmerman, \& van der Poel, 2016). The world's highest rates of infertility are in low- and middle-income countries (LMICs) (Mascarenhas, Flaxman, Boerma, Vanderpoel, \& Stevens, 2012) ${ }^{1}$. Although infertility

1 Regionally, Mascarenhas et al. (2012) estimate that, as of 2010, $\sim 1 \%$ of all women experience primary infertility (childlessness), compared to $2 \%$ or more in South Asia and North Africa and the Middle East. Secondary infertility (subsequent to the birth of a child) estimates highlight greater regional disparities, with $1.3 \%$ of women in high-income countries affected, compared to between $1.8 \%$ (Latin America and the Caribbean) and 5.6\% (sub-Saharan Africa-SSA) in low- and middle-income regions. These figures also mask within-region disparities. For example, Guatemala's secondary infertility rate of $4.4 \%$ far exceeds the regional $1.8 \%$ figure, as does the $9.6 \%$ figure for Djibouti in comparison to the $5.6 \%$ regional figure for SSA. When primary and se-

${ }^{\star}$ Corresponding author: j.fledderjohann@lancaster.ac.uk

Department of Sociology, Lancaster University

(c) BY-NC-ND (C) 2018 Jasmine Fledderjohann, Celia Roberts 
can be a problem of both male and female bodies and/or their coming together, studies of infertility overwhelmingly focus on women's experiences and female bodies (Greene \& Biddlecom, 2000; Marsiglio, Lohan, \& Culley, 2013; Slauson-Blevins \& Johnson, 2016). Men, male bodies, and men's reproductive experiences remain largely invisible in this work (see for notable exceptions e.g. Agarwal, Mulgund, Hamada, \& Chyatte, 2015; Barnes, 2014; Bell, 2015, 2016, Inhorn, 2002, 2012; Parrott, 2014). Sex/gender is typically figured as straightforwardly biological and binary in this field. Bodies and individuals who do not identify as typical 'men' or 'women' are generally absent. Here, we draw on contemporary theories of gender as 'performed' and of bodies as 'enacted' to argue that in/fertility surveys are part of a highly complex set of forces and actors producing both in/ fertility and sexed/gendered bodies.

Gender is a social phenomenon, continuously produced in and through the cultural exchanges, practices and institutions that Connell (1987) labels 'gender regimes'. Over time and through generations, gender regimes become core parts of subjectivities: gender is lived practically and materially in the world, but also internally in our thoughts and feelings (Harris, 2009). Poststructuralist feminist theorists, most notably Butler, have more radically argued that sex can also be conceptualised along these lines. Rather than a biological underpinning, sex is understood as 'performed'-brought into being through practices constituting gender regimes, despite being experienced as if they were inevitable physical truths (Butler, 1990, 1993, 2004). Importantly, feminist theorists, including Butler, also argue that contemporary relationships between sex and gender are frequently 'troubled': the physical elements of sex/ gender have become sites for pharmacological and surgical control, whilst new reproductive technologies have profoundly shifted our understandings of the significance of biological differences between men and women (Braidotti, 2013; Fausto-Sterling, 2012; Franklin \& Roberts, 2005; Roberts, 2007; Thompson, 2005). Reproduction no longer requires heterosexual intercourse and is not the exclusive preserve of couples. This large and complex body of work holds great significance for empirical studies of in/fertility

condary figures are combined, more than $10 \%$ of the population is impacted in some countries, representing a sizable minority. The consequences of infertility are often particularly severe in LMICs, where prevalence is also highest (Rouchou, 2013; Stellar et al., 2016). because it suggests that sex and gender do not preexist human practices but instead continuously come into existence though cultural practice in all its forms, including survey research.

The idea that sex/gender are performed resonates with work from science and technology studies arguing that bodies, and embodied experiences such as 'in/fertility', are literally made through medical and scientific practices. Mol (2002), for example, describes bodies with atheroschlerosis as 'enacted' through clinical (and lay) practices of measuring, diagnosing and intervening. In work on early onset puberty, Roberts (2015) relatedly argues that biomedical and technoscientific practices of measuring, assessing, studying, classifying and treating pubescent bodies are increasingly significant modes of making sex/gender. Working with these ideas, in this paper we ask how, and with what consequences, do large-scale surveys enact particular versions of sex/gender and reproduction in their attempts to document in/fertility? This builds on existing work documenting men's exclusion from reproductive health research (Agarwal et al., 2015; Dudgeon \& Inhorn, 2003; Fledderjohann \& Barnes, 2018; Inhorn \& Patrizio, 2015; Inhorn, Tjørnhøj, Goldberg, \& la Cour Mosegaard, 2009; Marsiglio et al., 2013; Wentzell \& Inhorn, 2014) by examining specifically the treatment of gender and infertility in survey research. Following extant demographic research using survey data in LMICs (e.g. Larsen, 2005), we examine infertility broadly-inclusive of a range of psychosocial and biological conditions (e.g. impotence, low sperm count) that may limit the ability to have a live birth-rather than focusing narrowly on clinical measures of subfecundity. This reflects our focus on common practice in the collection and analysis of survey data rather than practice in clinical settings.

Most existing evidence on infertility comes from measures constructed ${ }^{2}$ from fertility data in large-

2 In clinical settings, infertility is typically defined as $12+$ months of regular, unprotected intercourse without a conception (WHO, 2015). Measurement in survey data is more complex. Some surveys in the US collect data on whether individuals have ever received a medical diagnosis, start and end dates of relationships, histories of contraceptive use and intercourse, and details of pregnancies and live births (see, for example, IFSS, n.d.; D. R. Johnson \& White, n.d.). Using these data on relationship, contraceptive use, and pregnancy histories, it is possible to construct measures of infertility-that is, to examine how long couples have had unprotected intercourse, and to determine whether their duration of unprotected intercourse matches biomedical definitions. In LMICs, data on medical diagnosis are rare, and 
scale cross-sectional surveys or small, highly selective clinical samples. Particularly in LMICs, large-scale cross-sectional surveys produce representative data and generalizable inferences and are thus widely used for estimating global prevalence and shaping policy around reproductive health, rights, and access (Greene \& Biddlecom, 2000, 2000; Larsen, 2000; Solinger \& Nakachi, 2016). Yet such data have the potential to render some groups and/or issues invisible (Fledderjohann \& Barnes, 2018). Here, we examine two ways in which in in/fertility surveys render men invisible and produce limiting enactments of sex/gender: 1) exclusionary conceptualization of the population and 2) selection out through instrument design. We then present the DHS as a case study of these processes in LMIC surveys.

\section{Enacting exclusions in in/ fertility research}

\section{Defining Populations at Risk}

Survey research often aims to generate a representative sample of a population of interest. A first step is to accurately identify the population at-risk. In the case of in/fertility surveys, this has often been defined as women aged $\sim 15-49$, with men frequently underrepresented or entirely excluded (Greene \& Biddlecom, 2000; Slauson-Blevins \& Johnson, 2016). While men's exclusion is often justified based on pragmatic considerations, existing research shows that such exclusions are not merely pragmatic, but most commonly derive from the cultural perception that reproduction is a female domain (Slauson-Blevins \& Johnson, 2016). Moreover, significant practical challenges also arise when obtaining in/fertility data from women (see for example Casterline, 1989), but concerted effort has been invested in overcoming these pragmatic considerations. That the same effort has

reproductive, contraceptive, and relationship histories are often less detailed; using these less detailed data, demographers apply a similar method of constructing measures of infertility, but extend the requisite time spent 'trying' to conceive in order to rule out the possibility of other unmeasured but potentially relevant influences on in/fertility (Larsen, 2005). Some surveys may also include self-identified infertility-that is, individuals' own assessments of their capacity to conceive/carry a pregnancy to term (Fledderjohann \& Johnson, 2015; D. R. Johnson \& White, n.d.; Leonard, 2002). not been invested in men's data (Greene \& Biddlecom, 2000) both reflects and remakes gender asymmetries in research and cultural norms around reproduction.

Men's invisibility in fertility surveys is not exclusively a problem of LMICs; for example, the Integrated Fertility Survey Series, a key data source for research on reproduction in the US since 1955, did not include male respondents until 2002 (Fledderjohann \& Barnes, 2018; IFSS, n.d.). However, men's reproductive histories and intentions have increasingly been included in surveys and qualitative data in high-income countries. A growing number of high-quality cross-sectional and prospective cohort studies undertaken in these settings involve men and include survey items relating to in/fertility (e.g. IFSS, n.d.; D. R. Johnson \& White, n.d.). This literature demonstrates that we miss both commonalities and differences between women's and men's experiences when men are excluded, and that there are unique insights about gender, relationships, and reproduction to be gained by viewing infertility as a dyadic process (see for example Barnes, 2014; Bell, 2015; Greil, Leitko, \& Porter, 1988; Hadley \& Hanley, 2011).

\section{Survey Instrument Design}

Surveys may also exclude certain groups or issues through their design (e.g. skip patterns, question wording): for example desire to have a(nother) child is often taken to be a prerequisite for 'trying' to conceive and therefore being at-risk of infertility. In surveys where complete reproductive information is collected only for individuals who desire to conceive, infertility among those who do not desire to have (more) children is excluded. This issue is highlighted in work on the 'hidden infertile'-women who report a history of 12+ months of unprotected intercourse but do not identify as 'trying to conceive' (Greil, McQuillan, Johnson, Slauson-Blevins, \& Shreffler, 2010). Using the NSFB, Greil et al. identify 2,286 women who report $12+$ months of regular, unprotected intercourse that did not result in a pregnancy. Of these $48.7 \%$ were infertile without the intent to conceive. Such individuals would be entirely missed based on a measure in which infertility is contingent on fertility desires. This oversight is particularly problematic where the aim is to calculate the prevalence of infertility. Moreover, as Greil et al. note, some women may not be aware of/ have access to medical options for conception and may therefore have stopped 'trying' to conceive despite their experience of infertility. Such respondents 
remain hidden if those who are not currently trying to conceive are omitted.

Additionally, questions posed to the respondent may be worded in an exclusionary way or may not include a suitable response category. Greil's (1991) work on infertility in the US showed that although women may suspect infertility to the point of seeking treatment, they may opt to label themselves 'not yet pregnant' rather than 'infertile'. Survey items requiring women to label themselves explicitly as 'infertile' may thus underestimate suspected difficulties conceiving. Engaging with infertility services and/or reproductive medicine can also render a woman more infertile than she previously felt herself or was medically recognised to be (K. Johnson \& Fledderjohann, 2012). Reproductive medicine practices enact new kinds of infertility: a couple may produce high quality embryos which never implant; they may achieve biochemical pregnancies but never give birth. Indeed, reproductive medicine practices can produce infertility even in those who have never experienced it, as demonstrated by the experiences of those using IVF techniques to genetically screen embryos through pre-implantation genetic diagnosis (Franklin \& Roberts, 2005). Such examples indicate that 'infertility' is the outcome of a set of material-discursive practices, rather than a specific bodily condition of bodies or relations between bodies. Infertility, in other words, is enacted. Survey questions are an important vector of such enactments.

Some essential issues may also be omitted from surveys. For instance, questions around self-identified infertility-perceived inability to conceive-are often excluded from surveys in LMICs. Whilst it is possible to construct measures of infertility based on the time spent trying to conceive, contraceptive use, starting dates of relationships, and maternity histories, the alignment between such constructed measures and women's own assessments of their infertility is low (Fledderjohann \& Johnson, 2015). This is important given evidence that self-identified infertility may be more salient to social outcomes (e.g. relationship stability, stigma) than such constructed measures (Fledderjohann, 2017; Leonard, 2002; Okonofua, Harris, Odebiyi, Kane, \& Snow, 1997). Nor would 'impatience to conceive'-self-identification of fertility problems before there is a strong biomedical reason to suspect infertility (Leridon, 1991)-be perceptible through constructed measures. In sum, even where all sociodemographic groups are included in samples, survey instrument design may omit specific reproductive experiences of some respondents.

\section{Data and Methods}

In/fertility research enacts in/fertility in specific ways by excluding particular forms of data and knowledge through sampling and instrument design. As a case study, we explore how the Demographic and Health Surveys (DHS), one of the most widely used and consistently collected large-scale data sources for LMICs, render men's infertility invisible. The crosssectional DHS data were first collected in the mid1980s and are now available for 90 countries (Corsi, Neuman, Finlay, \& Subramanian, 2012; USAID, n.d.-b). A standardized ${ }^{3}$ core questionnaire, which facilitates cross-national comparisons, is administered by faceto-face interview (USAID, n.d.-a). The questionnaires have changed several times since the program's inception; each revision of the core questionnaire corresponds to a new 'Phase', with the most recent being Phase 7 (USAID, 2017). The data have been widely used to estimate infertility prevalence in LMICs using constructed infertility measures (Larsen, 2000, 2005; Mascarenhas et al., 2012; Polis, Cox, Tunçalp, McLain, \& Thoma, 2017).

Using the list of data available for download on the DHS website (USAID, 2017), we created a dataset consisting of survey year, whether men's and women's surveys were available, inclusion criteria (age, marital status) for men and women, and the Phase deployed. From this, we also calculated how many men's surveys there are as a proportion of women's. We excluded non-standard surveys ${ }^{4}$ : AIDS Indicator (AIS), Knowledge, Attitude and Practices (KAP), and Malaria Indicator (MIS) Surveys; special surveys; in-depth surveys; experimental surveys; and continuous

3 With minor adjustments to account for culturally-specific differences (e.g. dietary differences and food preferences). Additional optional modules are also possible, but their use and implementation varies from country to country.

4 Notably, men's surveys are themselves technically considered special surveys; men's surveys have of course been included in our data here, however. Exclusion of non-standard Phases from the table resulted in the exclusion of Lao People's Democratic Republic, for which there is only a special survey in 2011-2012, Nigeria (Ondo State), for which there is only a 1986 special DHS available, and a reduction in the number of surveys in some other countries. We also excluded the 1992 survey for Guinea and the 2000-01 survey for Mauritania; while the type of survey is listed as 'Standard DHS' on the data download site, the Phase is listed as 'Other' for these countries, and so is not reconcilable with the questionnaire formats we examine here. 
surveys (USAID, 2017). In total, we assembled data for 88 countries, 255 women's surveys, and 174 men's surveys from $1985-2015^{5}$.

We compiled descriptive statistics and graphic displays to examine the availability of surveys across time and place. To test the hypothesis that the availability of men's DHS data has increased over time, we fit a bivariate logistic regression model-that is, a logistic regression model with whether a men's survey was available (yes=1) regressed on survey year (1985-2015). Descriptive statistics, maps, and logistic regression results were compiled using Stata v.13. We also applied qualitative directed content analysis (Hsieh \& Shannon, 2005), applying the notion of survey instrument design as a tool for enactment of exclusion outlined above to examine question wording and skip patterns in the DHS instruments, looking specifically at the DHS Phase 6 and Phase 7 instruments. Initially, we identified all questions in the instruments relevant to articulating in/fertility. We then examined both question wording and skip patterns to assess whether and/or how specific groups of people or experiences of infertility might be excluded. To facilitate a clearer understanding of potentially omitted groups based on these elements of the survey's instrument design, we created flow charts of the progression through the relevant reproductive health sections of the questionnaire.

\section{Results}

\section{Defining Populations at Risk}

In considering how DHS sampling may render men's infertility invisible, we asked first whether men were sampled and, second, where men were sampled, whether somesub-groups were excluded by population definitions. Table 1 provides descriptive statistics for our compiled data ${ }^{6}$. All DHS surveys sampled women, while only $67 \%$ sampled men. Countries had a mean of nearly three women's surveys (2.90), but of just under two (1.95) men's surveys. On the whole, the availability

5 There were no 2016-17 data available at the time this article was written.

6 Table A1 provides a complete list of our raw data. The data in Table A1 provide a breakdown of availability of surveys by gender and survey year, details of the survey phase in each year, and information about the inclusion criteria for men and women by age and marital status. Data are sorted alphabetically by country name and, within countries, in reverse chronological order. of men's surveys has increased over time; in countries where men were not sampled, men's exclusion tended to be in earlier years ${ }^{7}$. To test the hypothesis that availability of men's surveys has increased over time, we fit a bivariate logistic regression model. We found a positive association between year of survey administration and the availability of a survey that focused on men (OR=1.15; $\mathrm{p}<0.001)$.

Nearly one-fifth $(18.2 \%)$ of countries with at least one standard DHS survey have never had a men's survey. To some extent, this reflects that some countries only have data available in the earliest years of the DHS, when men's data were less frequently collected; yet this observation does not resolve the issue of men's reproductive invisibility in these countries. We observed regional patterning in survey availability, shown in Figure 1. Lighter colours indicate fewer surveys. Countries with no men's surveys are disproportionately concentrated in Latin America, North Africa and the Middle East, and Southeast Asia, while the highest number of men's surveys are found in SSA. Next, to address variation in the availability of data by country, we looked at how many men's surveys there are as a proportion of women's surveys (Figure 2). Though there is considerable variability from year to year, particularly in the 1990s, in general the proportion has increased over time, reaching $100 \%$ in 1999, 2004, 2009, 2011, and 2015. There is a geographic patterning to these data as well; the highest proportions of men's to women's surveys are found in SSA, with rates at or above the $75 \%$ mark in nearly all surveyed countries in SSA (Figure 3).

Finally, we considered how inclusion criteria by age and marital status may obscure some in/fertility, even where men are sampled. Table 1 shows that in some cases, men of all ages are included ${ }^{8}$. Where a numeric inclusion criterion for men's age is applied, this can range from 12 to 59 to ages 20+. Ages 15 to 59 is the most common criterion: $51.7 \%$ of men's surveys use this. Nearly half of surveys are spread across 12 other possible age range categories. While the age inclusion criterion is not entirely consistent for women ${ }^{9}$, there

7 There are some exceptions to this pattern. In Nicaragua, for example, a men's survey was administered in 1998, but no men's survey was administered in the next (and final) DHS in 2001. Similarly, while Bangladesh had men's surveys in 1993 through 2011, they did not collect data from men in 2014.

8 This tends to be the case where only men who are married to female respondents are sampled; implicitly, if you are of an age to be married, you are of an age to be included in the sample.

$994.9 \%$ of surveys apply a 15 to 49 age criterion for women's 
is a great deal more variability in age criteria for men. This greater fluctuation may in part reflect uncertainty around the limits of paternal age; less research exists on this topic, and considerable cultural ambiguity persists about men's reproductive lifespans (Greene \& Biddlecom, 2000; Sartorius \& Nieschlag, 2009). In countries with a more restrictive inclusion criterion for men's age, reproductive experiences of men outside of the upper and lower bounds are obfuscated. While $87.4 \%$ of men's surveys included men of any marital status, around one-eighth of surveys required men to be either ever-married (4.6\%), currently married (2.3\%), or married to the female respondent sampled (5.7\%). When sampling only ever-married men, the in/fertility of single men is missed entirely. Likewise, surveys that sample only currently married men or the husbands ${ }^{10}$ of female respondents render the infertility of both single and divorced men invisible; this may be particularly problematic where the risk of

inclusion, but in some cases girls as young as 10 are included. In less than $1 \%$ of women's surveys, the higher bound is 44 years. Again, Bangladesh is an example of a somewhat unusual case, with women's age range for inclusion being 15 to 49 in most years, but including women as young as 12 in 2011 and as young as 10 in 1993-94, 1996-97,1999-2000 and 2004.

10 This inclusion criterion also opens the survey to the issues of gender, information management, and gatekeeping discussed by Slauson-Blevins and Johnson (2016). divorce is higher for infertile couples (Fledderjohann, 2017). In short, inclusion of men as a group is not sufficient to ensure visibility for all men.

\section{Survey Instrument Design}

Survey instrument design has the potential to render invisible some groups or issues that are included in survey samples. Here, we look specifically at the collection of subjective infertility data in the DHS ${ }^{11}$. Our discussion here focuses on Phases 7 and $6^{12}$. There is no direct subjective self-identification question in the DHS questionnaires ${ }^{13}$. However, the instruments

11 Arguably, infertility is not a primary focus of the DHS-yet the use of the terminology 'couple infecund' in this self-reported response category suggests at least some interest in tracking infertility. Moreover, if the DHS do not aim to track infertility, this in itself is an egregious omission, with considerable implications for how we define and measure reproductive health and choice in LMICs. If we collect rich data on infertility in the Global North but fail to track infertility in LMICs, what are the implications for the stratification for reproduction on a global scale? 12 While it is possible to download a standardized men's questionnaire for Phases 5-7, in previous Phases the questionnaires are country-specific, and must be obtained on an individual basis in the appendix of relevant country reports. Due to this country-specific variation, it is not feasible to generalize about the infertility measures deployed prior to Phase 5.

13 For example, the US National Survey of Fertility Barriers in-

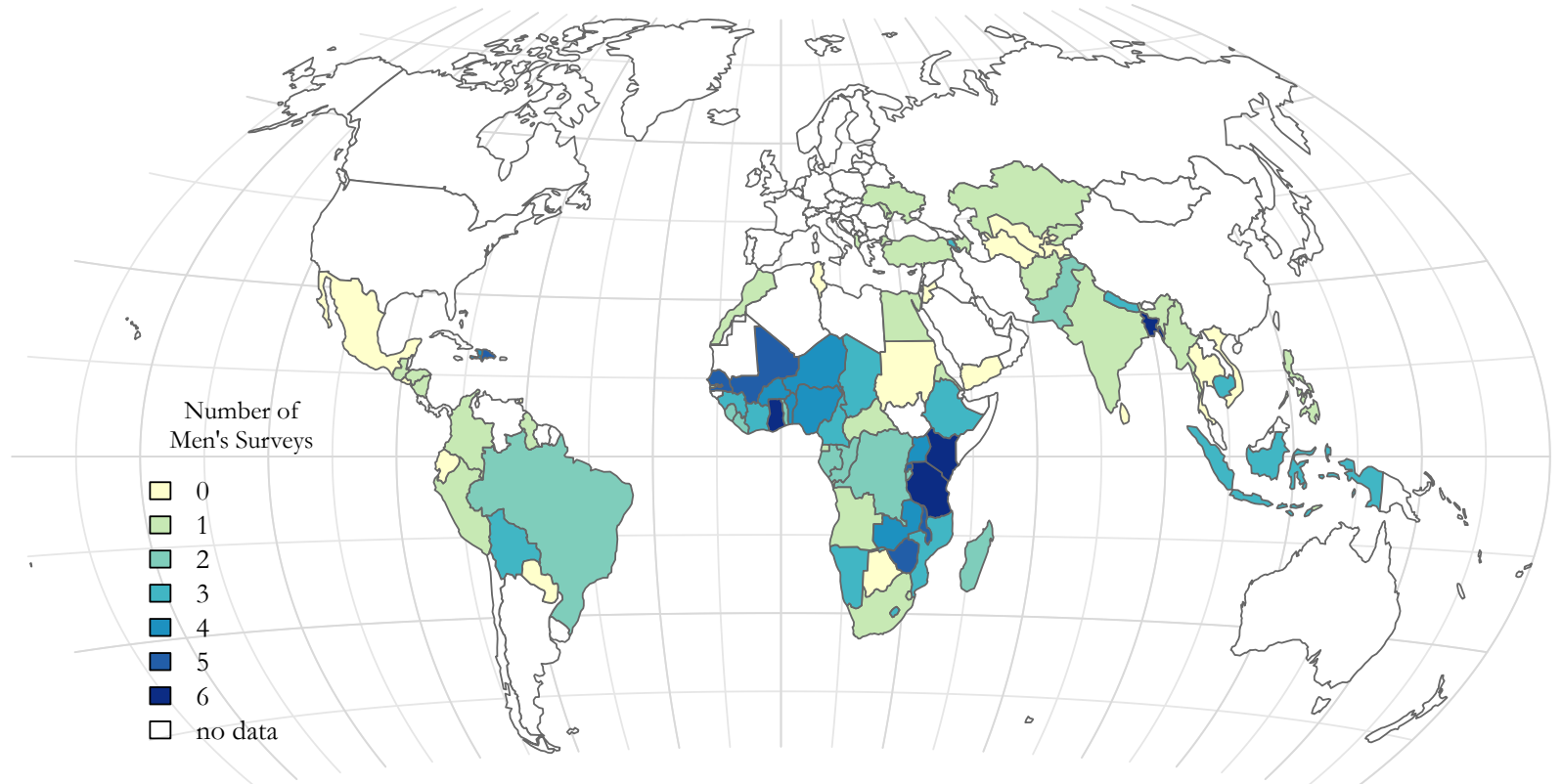

Figure 1. Total number of men's surveys, DHS for 83 countries, 1985-2015. Notes: Cape Verde, Maldives, Comoros, Samoa, and Sao Tome and Principe not shown due to map scale. The map drawn here shows no data for the Republic of South Sudan because the data run through 2015; however, South Sudan would have been covered by DHS data for Sudan in 1989-90, which is the only period for which DHS data were collected in Sudan. Data for these countries available in Appendix Table 1. 
Table 1. Descriptive statistics of DHS survey characteristics

\begin{tabular}{|c|c|c|c|c|c|}
\hline & $\begin{array}{l}\text { Number } \\
\text { of cases }\end{array}$ & Mean or $\%$ & Std. Dev. & $\begin{array}{l}\text { Minimum } \\
\text { Value }\end{array}$ & $\begin{array}{l}\text { Maximum } \\
\text { Value }\end{array}$ \\
\hline Proportion women's surveys & 255 & $100.0 \%$ & 0.00 & 1 & 1 \\
\hline Proportion men's surveys & 255 & $67.5 \%$ & 0.47 & 0 & 1 \\
\hline Number of men's surveys per country & 88 & 1.95 & 1.69 & 0 & 6 \\
\hline Number of women's surveys per country & 88 & 2.90 & 1.86 & 1 & 7 \\
\hline \multicolumn{6}{|l|}{ Age (Men) } \\
\hline 12 to 59 & 174 & $0.6 \%$ & 0.08 & 0 & 1 \\
\hline 13 to 59 & 174 & $0.6 \%$ & 0.08 & 0 & 1 \\
\hline 15 to 49 & 174 & $11.5 \%$ & 0.32 & 0 & 1 \\
\hline 15 to 54 & 174 & $16.1 \%$ & 0.37 & 0 & 1 \\
\hline 15 to 59 & 174 & $51.7 \%$ & 0.50 & 0 & 1 \\
\hline 15 to 60 & 174 & $0.6 \%$ & 0.08 & 0 & 1 \\
\hline 15 to 64 & 174 & $8.6 \%$ & 0.28 & 0 & 1 \\
\hline $18+$ & 174 & $0.6 \%$ & 0.08 & 0 & 1 \\
\hline 20 to 54 & 174 & $1.1 \%$ & 0.11 & 0 & 1 \\
\hline 20 to 55 & 174 & $0.6 \%$ & 0.08 & 0 & 1 \\
\hline 20 to 64 & 174 & $0.6 \%$ & 0.08 & 0 & 1 \\
\hline $20+$ & 174 & $1.7 \%$ & 0.13 & 0 & 1 \\
\hline All & 174 & $5.7 \%$ & 0.23 & 0 & 1 \\
\hline \multicolumn{6}{|l|}{ Age (Women) } \\
\hline 10 to 49 & 255 & $2.0 \%$ & 0.14 & 0 & 1 \\
\hline 12 to 49 & 255 & $0.8 \%$ & 0.09 & 0 & 1 \\
\hline 13 to 49 & 255 & $1.6 \%$ & 0.12 & 0 & 1 \\
\hline 15 to 44 & 255 & $0.8 \%$ & 0.09 & 0 & 1 \\
\hline 15 to 49 & 255 & $94.9 \%$ & 0.22 & 0 & 1 \\
\hline \multicolumn{6}{|l|}{ Marital Status (Men) } \\
\hline Any & 174 & $87.4 \%$ & 0.33 & 0 & 1 \\
\hline Ever married & 174 & $4.6 \%$ & 0.21 & 0 & 1 \\
\hline Currently married & 174 & $2.3 \%$ & 0.15 & 0 & 1 \\
\hline Married to female respondent & 174 & $5.7 \%$ & 0.23 & 0 & 1 \\
\hline \multicolumn{6}{|l|}{ Marital Status (Women) } \\
\hline Any & 255 & $81.6 \%$ & 0.39 & 0 & 1 \\
\hline
\end{tabular}




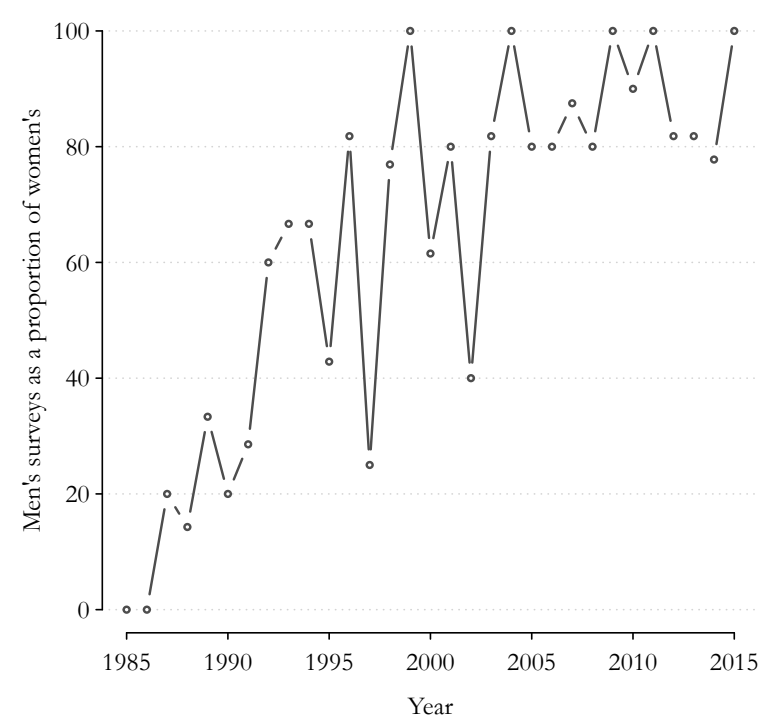

Figure 2. Men's surveys as a proportion of women's by year across 88 countries, 1985-2015

include some version of items about 1) desire for and 2) timing of a(nother) child. One possible response category to these items is: 'says couple can't get pregnant/couple infecund/he or all his wives or partners are infecund.' However, not all respondents have an opportunity to respond.

Figure 4 depicts the skip pattern leading to the relevant survey items in the Phase 7 questionnaire. In order to be asked about desire for children, men must be married or living with a partner, must not be sterilized, and must not have/know of any pregnant live-in partner. Men who reply that they want a(nother) child-that is, do not reply no/don't know/undecided/ can't get pregnant/partner sterilized-then proceed to another question about when they would like to have (additional) children. Categories include a specified number of months or years, 'soon or now', 'can't get pregnant', 'other,' and 'don't know.' Implicitly, then, men cannot be enacted as infecund if they are not currently partnered, are sterilized or have a pregnant partner. Infertility among men who, for example, are not partnered precisely because of previous fertility problems would be missed.

To understand how the questionnaire has changed between Phases, we completed the same mapping exercise for Phase 6 (Figure 5). Again, men must be married or living with a partner and unsterilized to be

cludes both 'Do you think you have/have had/might have trouble getting pregnant' and 'Do you think you have/have had a fertility problem' in order to assess self-identified infertility (D. R. Johnson \& White, n.d.). asked the relevant questions. The pattern for men who don't have/know of any pregnant live-in partner, and for those with a pregnant partner who doesn't want another child (or are unsure), is the same in DHS 6 and DHS 7. For men with pregnant partners who do want another child, however, the pattern differs. These men are still asked about timing for a next birth at this stage; however, unlike in DHS 7, the Phase 6 questionnaire includes 'couple infecund' as a response category for monogamously married men, and he/all wives or partners infecund' for polygynous marriages. This suggests increased invisibility for infertile men with a pregnant partner from Phase 6 to Phase 7.

There are also problems with the questions themselves. First, the response categories treat individual assessments of own fecundity and couple-level infertility as though they are equivalent phenomena. Yet if a man suspects his partner is infertile but he is capable of conceiving, his sexual and reproductive behaviour might vary dramatically compared to if he identifies himself as infertile. Further compounding this problem, the question is not asked separately for each wife in polygynous marriages. A man who is capable of conceiving with one wife but not with another may not indicate 'can't get pregnant' overall, despite his couple-specific difficulties ${ }^{14}$. Such distinctions would be missed entirely by this question construction. Administered via personal interview, the survey also requires interviewers to interpret the respondent's answer to this question and select the appropriate response category from listed options. How strongly must a respondent assert his subfecundity in order for interviewers to select the 'can't get pregnant/infecund' response? In a similar vein, if a man has an ideal timing in mind for the birth of a child but also suspects infertility, how would he

14 The women's questionnaire also includes items on desire for and timing of a(nother) child, with response categories including 'can't get pregnant'. Arguably, couple-specific difficulties conceiving could be ascertained by pairing men's data with reports from their partners. Yet this again conflates individual perceptions with couple-level infertility, and further implies that women's data can be used in place of men's detailed reports. Moreover, it raises a pragmatic problem: if a man reports specific timing for his next birth, but one of his wives reports that the couple can't get pregnant, how should these two reports be reconciled? Do the husband and wife have discordant perceptions of their ability to conceive? Was the husband answering with one of his other partnerships in mind? Substantial ambiguity is introduced by not collecting partnership-specific data on men's subjective assessments, even where men's data can be paired with reports from their partners. 


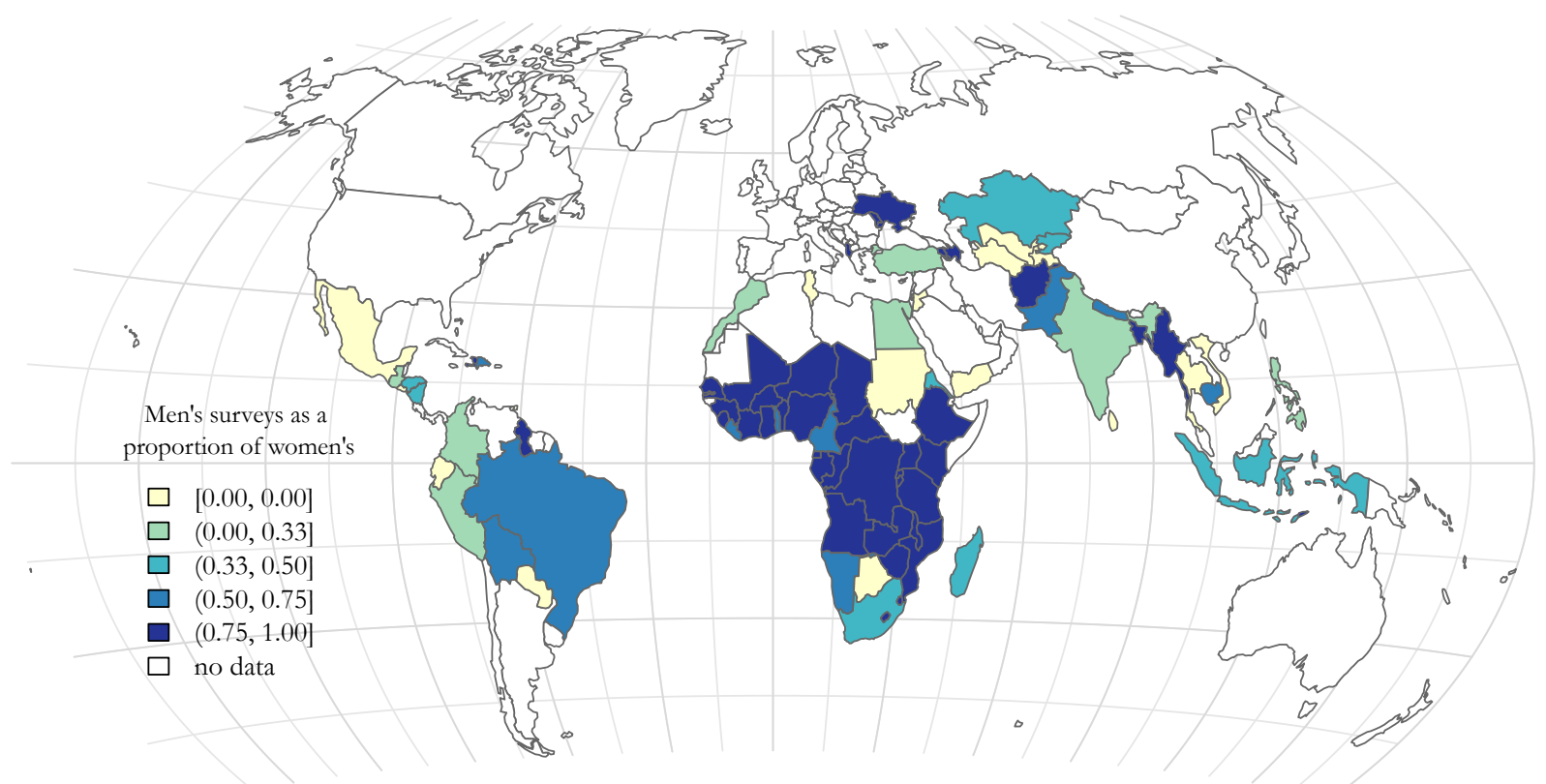

Figure 3. Men's surveys as a proportion of women's, DHS for 83 countries, 1985-2015. For Notes see Figure 1.

answer this question? If he expressed this ambiguity to the interviewer, how would his response be recorded?

Additional ambiguity is introduced by miscarriages, on which men do not report ${ }^{15}$. In Phase 7, only currently partnered, unsterilized men with wives who are not currently pregnant are asked the question about fertility preferences which enable them to indicate suspected infertility. Yet a man with a pregnant wife with a history of miscarriages may also worry about fertility problems-indeed inability to carry a pregnancy to term is defined as infertility by the WHO (2015). In Phase 6, men whose partners are currently pregnant are able to answer the timing question which includes 'couple infecund' as a response category-but only if they want another child. How would a man who wants no more children if the current pregnancy results in a live birth but who also harbours concerns about the couple's ability to carry the pregnancy to term, respond to this question?

While not directly related to the measurement of

15 One might argue that men do not experience miscarriages directly, and so their reports on miscarriage are not relevant. However, this argument reinforces the notion that men's bodies are 'non-reproductive'-incapable of the physical task of carrying children-and thereby also problematically reinforcing the notion of fatherhood as non-vital to masculinity/men's identities (Inhorn, Tjørnhøj, Goldberg, \& la Cour Mosegaard, 2009). Moreover, there is emerging evidence to suggest that sperm quality and advanced paternal age are associated with the risk of spontaneous abortion, highlighting the value of data on and from men (Kleinhaus et al., 2006; Liu et al., 2011). infertility per se, it is also worth noting that the DHS does not include any self-reported measures of gender identity, gender transition, or sexual orientation. The DHS thus assumes and enacts typical gender/ sex relations and embodiments and heterosexuality, thereby reinforcing a heteronormative view of family building.

\section{Discussion}

Survey research on infertility, including the DHS, enacts particular versions of in/fertility and sexed/ gendered bodies. Although scientifically precise, these instruments are not neutral in their operation: their design, question wording, and foci all contribute to the making of the objects they intend to survey. What might be the consequences of the in/fertility surveys analysed here for wider understandings and embodied experiences of sex/gender and reproduction?

As Epstein (2007) argues, contemporary medical research most commonly relies on a 'difference/ inclusion paradigm' that attempts to pay attention to the different kinds of bodies participating in research and engaging with medical treatments. Importantly, Epstein notes that inclusion is not a panacea for inequities in the social construction of health, and can even serve to reinforce rather than resolve socially constructed differences. We suggest that in/fertility survey research is a notable area where men's historical exclusion has reinforced 


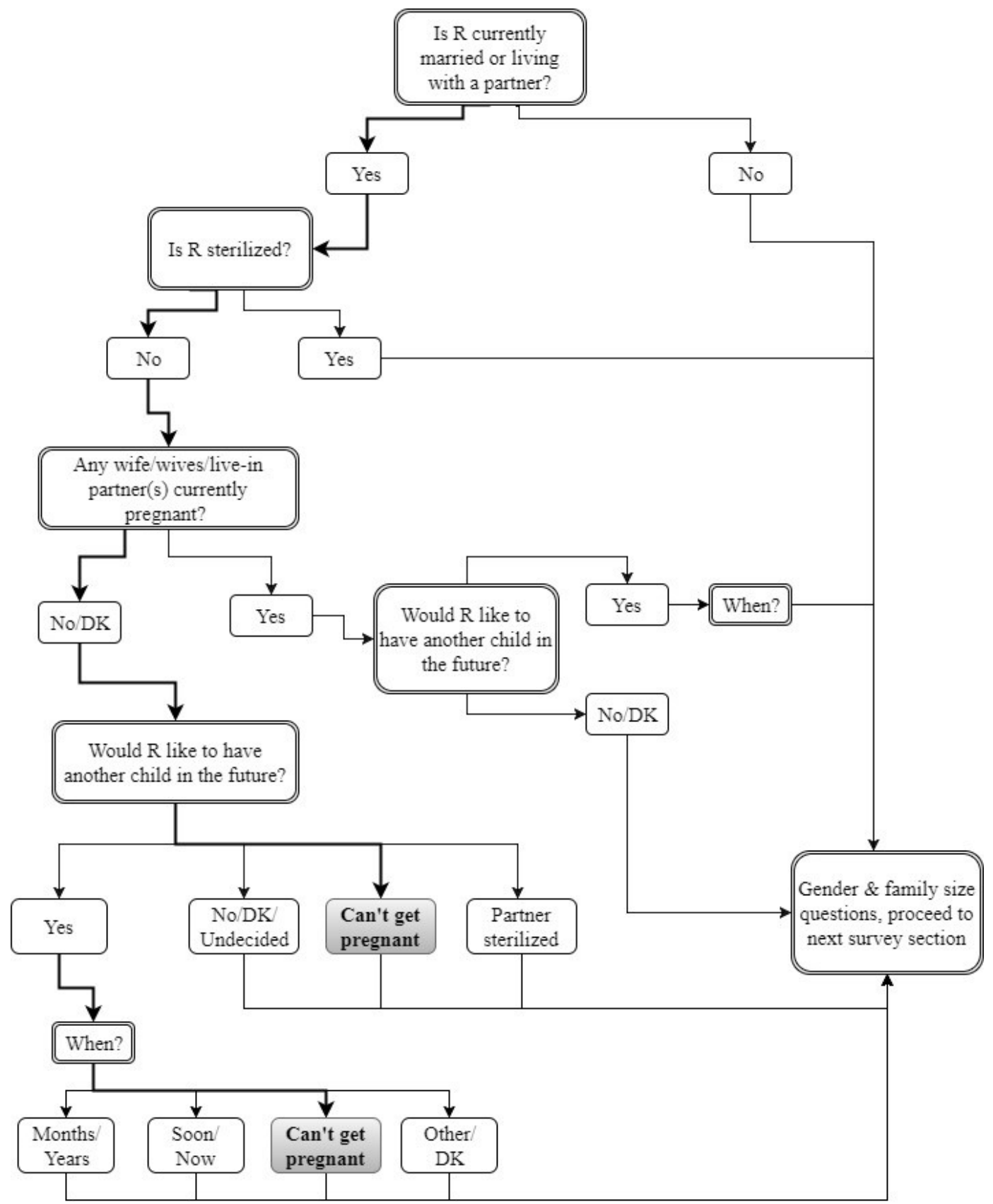

Figure 4. Flowchart of survey skip pattern in DHS Phase 7 men's questionnaire

gender norms around reproduction, and that, where men have been included, surveys have reinforced a problematic focus on reproductive difference rooted in gender essentialism. For instance, while our results demonstrate an increase in the availability of men's surveys over time, this analysis also shows that the availability of these surveys is geographically patterned, and the content of questionnaires insufficient to capture male in/fertility experiences.
The overwhelming focus of in/fertility survey research remains on women's bodies, with men and nonbinary-identified others almost completely missing. The capacity of many women to conceive and give birth renders this focus 'pragmatic,' even 'natural.'

In our view it is unhelpful, even harmful, to focus so strongly on women and female bodies in in/fertility research. The exclusion of men, male bodies and those who do not identify as binary in sex or gender terms 


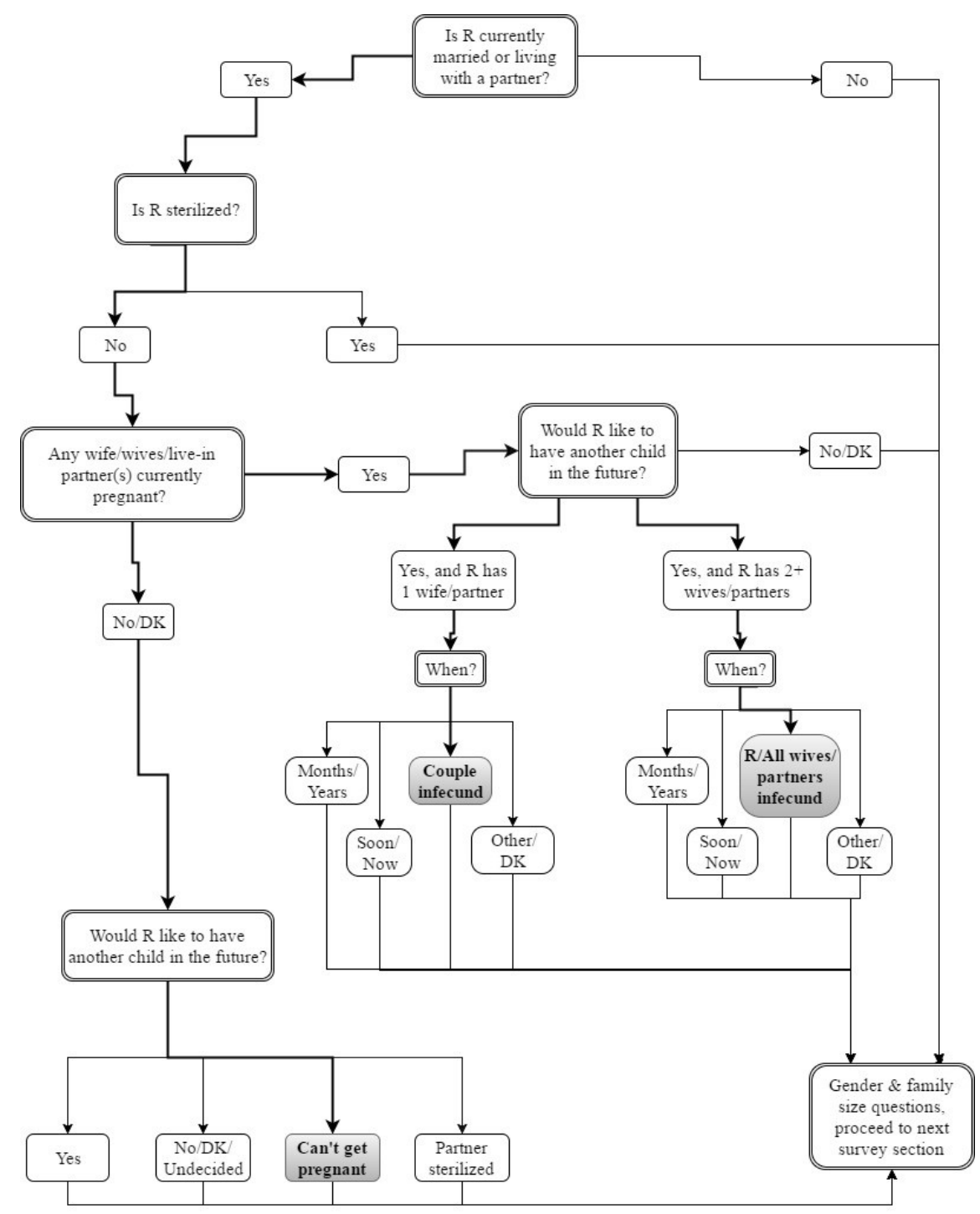

Figure 5. Flowchart of survey skip pattern in DHS Phase 6 men's questionnaire

lessens our capacity to understand and document reproductive processes across the life course and throughout the world. In addition to contributing to missing information on the incidence and prevalence of reproductive health issues among men and nonbinary others, their exclusion from survey samples also renders changing patterns of nuptiality and fertility more obscure. Men's invisibility also reinforces the burden of 'reproductive blame' placed on women (Inhorn, 2003). It is difficult to view reproduction as a (at least) dyadic process when men are missing from relevant research. Whilst publicly available secondary data resources such as the DHS are a tremendous asset, the ways in which the surveys work materially shape men's and women's lives: their data are used as an evidence-base for family and population policy, and reproductive health services are only available to those whose needs are recognized (Fledderjohann \& Barnes, 2018). Additionally, these data shape how in/ fertility is understood as a sociocultural phenomenon; lopsided representations of in/fertility unfairly places the responsibility for reproductive failure on women, while simultaneously obscuring and stigmatizing men's reproductive health needs (Greene \& Biddlecom, 2000).

Particularly in light of limited resources for survey research, it could be argued that changing population definitions reflect culturally-specific notions of family and fertility, and that it would be inefficient to collect data that do not reflect common family-building practices. For example, why expend resources to collect data from unmarried populations if the majority of fertility is within marriage? There are several reasons, however, why inclusive data collection is needed: first, 
it is precisely culturally-specific norms about family formation that shape survey design; gender is enacted in surveys through this process, and the process itself deserves examination. Second, all norms, including family-building ones, change. Collecting inclusive data enables us to track these changes. Rendering previously rare family-building events invisible shapes both the questions we are able to answer and the conclusions we draw. Finally, rendering some groups invisible for convenience is unjust. While there are clearly pragmatic considerations in data collection, limited resources being among these, there are also pragmatic consequences of not collecting data from some groups. Although we do not advocate a onesize-fits-all approach-survey tools can and should be nuanced and culturally-appropriate-it is important to carefully examine the unintended consequences for in/visibility and the enactment of gender involved in survey (and all forms of scientific) research. Policy initiatives, resource availability and ultimately bodies themselves are shaped by prevalent understandings of family-building patterns and needs.

Men's inclusion in survey data is, we argue, a necessary but not sufficient condition for greater equity in the interlinked arenas of reproductive health and justice. As evidenced by Epstein's (2007) examination of the politics of inclusion in research samples in the US, however, inclusion does not automatically ensure equity. Careful and frequently revisited consideration must be given to how and why individuals are included in data, and what the implications of this inclusion may be. Our examination of the DHS survey instrument has shown that even where men are present in survey samples, instrument design shapes the inclusiveness and quality of data collected. In a similar vein, while we have argued that men's invisibility has the potential to contribute to their inability to access medical resources and social support, unfettered access to these resources is unlikely to be a panacea for the social problem of infertility, and may in fact compound the stratification of reproduction (see for example Inhorn, 2003). Ultimately, the situation is highly complex, and must be considered more deeply. Reproductive surveys enact particular versions of sex/ gender and of in/fertility that shape policy decisions, clinical practices and embodied experience. They are best conceived, we suggest, not as neutral instruments but as world-making tools that may result in greater equality and justice if used with care.

\section{References}

Agarwal, A., Mulgund, A., Hamada, A., \& Chyatte, M. R. (2015). $A$ unique view on male infertility around the globe. Reproductive Biology and Endocrinology, 13(37), 1-9.

Barnes, L. W. (2014). Conceiving Masculinity: Male Infertility, Medicine, and Identity. Philadelphia: Temple University Press.

Bell, A. V. (2015). Overcoming (and Maintaining) Reproductive Difference: Similarities in the Gendered Experience of Infertility. Qualitative Sociology, 38(4), 439-458. https:// doi.org/10.1007/s11133-015-9315-2

Bell, A. V. (2016). 'I don’t consider a cup performance; I consider it a test': masculinity and the medicalisation of infertility. Sociology of Health \& Illness, 38(5), 706-720.

Braidotti, R. (2013). The Posthuman (First Edition edition). Cambridge, UK: Polity Press.

Butler, J. (1990). Gender Trouble and the Subversion of Identity. Abington, Oxfordshire and New York: Routledge.

Butler, J. (1993). Bodies That Matter: On the discursive limits of sex. New York: Routledge.

Butler, J. (2004). Undoing Gender. New York and Abington, Oxfordshire: Routledge.

Casterline, J. B. (1989). Collecting data on pregnancy loss: a review of evidence from the World Fertility Survey. Studies in Family Planning, 20(2), 81-95.

Connell, R. (1987). Gender and Power: The person, society and sexual politics. London: Polity Press.

Corsi, D. J., Neuman, M., Finlay, J. E., \& Subramanian, S. V. (2012). Demographic and health surveys: a profile. International Journal of Epidemiology, 41(6), 1602-1613.

Dudgeon, M. R., \& Inhorn, M. C. (2003). Gender, masculinity, and reproduction: Anthropological perspectives. International Journal of Men's Health, 2(1), 31.

Epstein, S. (2007). Inclusion: The Politics of Difference in Medical Research. London: University of Chicago Press.

Fausto-Sterling, A. (2012). Sex/Gender: Biology in a social world. New York: Routledge.

Fledderjohann, J. (2012). “Zero is not good for me": implications of infertility in Ghana. Human Reproduction, 27(5), 1383-1390. https://doi.org/10.1093/humrep/des035

Fledderjohann, J. (2017). Difficulties Conceiving and Relationship Stability in Sub-Saharan Africa: The Case of Ghana. European Journal of Population, 33(1), 129-152. https://doi.org/10.1007/s10680-016-9401-5

Fledderjohann, J., \& Barnes, L. W. (2018). Reimagining infertility: a critical examination of fertility norms, geopolitics and survey bias. Health Policy and Planning, 33(1), 34-40. https://doi.org/10.1093/heapol/czx148

Fledderjohann, J., \& Johnson, D. R. (2015). Impaired fertility and perceived difficulties conceiving in Ghana: Measurement problems and prospects. Journal of Biosocial Science, 48(4), 431-456. https://doi.org/10.1017/S0021932015000310

Franklin, S., \& Roberts, C. (2005). Born and Made: An ethnography of preimplantation genetic diagnosis. Princeton: Princeton University Press.

Greene, M. E., \& Biddlecom, A. E. (2000). Absent and problematic men: Demographic accounts of male 
reproductive roles. Population and Development Review, 26(1), 81-115.

Greil, A. L. (1991). Not yet pregnant: Infertile couples in contemporary America. New Jersey: Rutgers University Press.

Greil, A. L., Leitko, T. A., \& Porter, K. L. (1988). Infertility: His and hers. Gender \& Society, 2(2), 172-199.

Greil, A. L., McQuillan, J., Johnson, K., Slauson-Blevins, K., \& Shreffler, K. M. (2010). The hidden infertile: infertile women without pregnancy intent in the United States. Fertility and Sterility, 93(6), 2080-2083. https://doi. org/10.1016/j.fertnstert.2009.08.024

Hadley, R., \& Hanley, T. (2011). Involuntarily childless men and the desire for fatherhood. Journal of Reproductive and Infant Psychology, 29(1), 56-68.

Harris, A. (2009). Gender as soft assembly. New York and London: Routledge.

Hollos, M., Larsen, U., Obono, O., \& Whitehouse, B. (2009). The problem of infertility in high fertility populations: Meanings, consequences and coping mechanisms in two Nigerian communities. Social Science \& Medicine, 68(11), 2061-2068. https://doi.org/10.1016/j. socscimed.2009.03.008

Hsieh, H.-F., \& Shannon, S. E. (2005). Three Approaches to Qualitative Content Analysis. Qualitative Health Research, 15(9), 1277-1288. https://doi.org/10.1177/1049732305276687

IFSS. (n.d.). Integrated Fertility Survey Series user guide. ICPSR, University of Michigan. Retrieved from http://www. icpsr.umich.edu/icpsrweb/content/IFSS/documentation. html

Inhorn, M. C. (2002). Sexuality, masculinity, and infertility in Egypt: Potent troubles in the marital and medical encounters. The Journal of Men's Studies, 10(3), 343-359.

Inhorn, M. C. (2003). “The Worms Are Weak” Male Infertility and Patriarchal Paradoxes in Egypt. Men and Masculinities, 5(3), 236-256.

Inhorn, M. C. (2012). The new Arab man: Emergent masculinities, technologies, and Islam in the Middle East. Princeton University Press.

Inhorn, M. C., \& Patrizio, P. (2015). Infertility around the globe: new thinking on gender, reproductive technologies and global movements in the 21st century. Human Reproduction Update, 21(4), 411-426.

Inhorn, M. C., Tjørnhøj, T., Goldberg, H., \& la Cour Mosegaard, M. (2009). Reconceiving the Second Sex in Reproduction? Men, Sexuality, and Masculinity. New York: Berghahn Books.

Inhorn, M. C., \& van Balen, F. (2002). Infertility around the globe: New thinking on childlessness, gender, and reproductive technologies. Berkeley: University of California Press.

Johnson, D. R., \& White, L. (n.d.). National Survey of Fertilty Barriers [Computer File]. University Park, PA: The Pennsylvania State University Population Research Institute [distributor].

Johnson, K., \& Fledderjohann, J. (2012). Revisiting "her" infertility: Medicalized embodiment, self-identification and distress. Social Science \& Medicine, 75(5), 883-891. https://doi.org/10.1016/j.socscimed.2012.04.020
Kleinhaus, K., Perrin, M., Friedlander, Y., Paltiel, O., Malaspina, D., \& Harlap, S. (2006). Paternal age and spontaneous abortion. Obstetrics \& Gynecology, 108(2), 369-377.

Larsen, U. (2000). Primary and secondary infertility in sub-Saharan Africa. International Journal of Epidemiology, 29(2), 285-291.

Larsen, U. (2005). Research on infertility: Which definition should we use? Fertility and Sterility, 83(4), 846-852. https://doi.org/10.1016/j.fertnstert.2004.11.033

Leonard, L. (2002). Problematizing fertility: 'Scientific' accounts and Chadian women's narratives. In M. C. Inhorn \& F. Van Balen (Eds.), Infertility around the globe: new thinking on childlessness, gender, and reproductive technologies (pp. 193-214). Berkeley: University of California Press.

Leridon, H. (1991). Sterility and sub-fecundity: from silence to impatience? Population, 46(2), 225-47.

Liu, K., Case, A., Cheung, A. P., Sierra, S., AlAsiri, S., CarranzaMamane, B., ... others. (2011). Advanced reproductive age and fertility. Journal of Obstetrics and Gynaecology Canada, 33(11), 1165-1175.

Marsiglio, W., Lohan, M., \& Culley, L. (2013). Framing Men's Participation in the Procreative Realm. Journal of Family Issues, 34(8), 1011-1036.

Mascarenhas, M. N., Flaxman, S. R., Boerma, T., Vanderpoel, S., \& Stevens, G. A. (2012). National, regional, and global trends in infertility prevalence since 1990: a systematic analysis of 277 health surveys. PLoS Medicine, 9(12), e1001356.

Mol, A. (2002). The Body Multiple: Ontology in medical practice. Durham: Duke University Press.

Okonofua, F. E., Harris, D., Odebiyi, A., Kane, T., \& Snow, R. C. (1997). The social meaning of infertility in Southwest Nigeria. Health Transition Review, Health Transition Review, 7(2), 205-220.

Parrott, F. R. (2014). 'At the hospital I learnt the truth': diagnosing male infertility in rural Malawi. Anthropology \& Medicine, 21(2), 174-188.

Polis, C. B., Cox, C. M., Tunçalp, Ö., McLain, A. C., \& Thoma, M. E. (2017). Estimating infertility prevalence in low-to-middle-income countries: an application of a current duration approach to Demographic and Health Survey data. Human Reproduction, 32(5), 1064.

Roberts, C. (2007). Messengers of sex: hormones, biomedicine and feminism. Cambridge University Press.

Roberts, C. (2015). Puberty in Crisis: The sociology of early sexual development. Cambridge: Cambridge University Press.

Rouchou, B. (2013). Consequences of infertility in developing countries. Perspectives in Public Health, 133(3), 174-179. https://doi.org/10.1177/1757913912472415

Sartorius, G. A., \& Nieschlag, E. (2009). Paternal age and reproduction. Human Reproduction Update, 16(1), 65-79.

Slauson-Blevins, K., \& Johnson, K. (2016). Doing Gender, Doing Surveys? Women's Gatekeeping and Men's Non-Participation in Multi-Actor Reproductive Surveys. Sociological Inquiry, 86(3), 427-449. https://doi.org/10.1111/ soin.12122

Solinger, R., \& Nakachi, M. (Eds.). (2016). Reproductive States: Global Perspectives on the Invention and Implementation of Population Policy. Oxford ; New York: OUP USA. 
Stellar, C., Garcia-Moreno, C., Temmerman, M., \& van der Poel, S. (2016). A systematic review and narrative report of the relationship between infertility, subfertility, and intimate partner violence. International Journal of Gynecology \& Obstetrics, 133(1), 3-8.

Thompson, C. (2005). Making parents: The ontological choreography of reproductive technologies. Cambridge, MA: MIT Press.

USAID. (2017). Available datasets. Retrieved July 20, 2017, from http://www.dhsprogram.com/data/available-datasets.cfm

USAID. (n.d.-a). DHS Methodology. Retrieved August 15, 2013, from

USAID. (n.d.-b). DHS Program. Retrieved from http://www. dhsprogram.com/data/available-datasets.cfm.

Wentzell, E. A., \& Inhorn, M. C. (2014). Reconceiving masculinity and 'men as partners' for ICPD beyond 2014: insights from a Mexican HPV study. Global Public Health, 9(6), 691-705.

WHO. (2015). Infertility definitions and terminology. Retrieved October 25, 2015, from http://www.who.int/reproductivehealth/topics/infertility/definitions/en/ 


\section{Appendix}

Table A1. Availability of DHS data for 88 countries by year, DHS Phase, and gender

\begin{tabular}{|c|c|c|c|c|c|c|}
\hline Country & Survey Year & $\begin{array}{l}\text { DHS } \\
\text { Phase }\end{array}$ & $\begin{array}{l}\text { Women's Marital } \\
\text { Status }\end{array}$ & $\begin{array}{l}\text { Women's Age } \\
\text { Range }\end{array}$ & Men's Marital Status & $\begin{array}{l}\text { Men's Age } \\
\text { Range }\end{array}$ \\
\hline Afghanistan & 2015 & 7 & Ever Married & 15 to 49 & Ever Married & 15 to 49 \\
\hline Albania & 2008-09 & 5 & All & 15 to 49 & All & 15 to 49 \\
\hline Angola & $2015-16$ & 7 & All & 15 to 49 & All & 15 to 54 \\
\hline Armenia & 2010 & 6 & All & 15 to 49 & All & 15 to 49 \\
\hline Armenia & 2005 & 5 & All & 15 to 49 & All & 15 to 49 \\
\hline Armenia & 2000 & 4 & All & 15 to 49 & All & 15 to 54 \\
\hline Azerbaijan & 2006 & 5 & All & 15 to 49 & All & 15 to 59 \\
\hline Bangladesh & 2014 & 7 & Ever Married & 15 to 49 & -- & -- \\
\hline Bangladesh & 2011 & 6 & Ever Married & 12 to 49 & Ever Married & 15 to 54 \\
\hline Bangladesh & 2007 & 5 & Ever Married & 15 to 49 & Ever Married & 15 to 54 \\
\hline Bangladesh & 2004 & 4 & Ever Married & 10 to 49 & Ever Married & 15 to 54 \\
\hline Bangladesh & $1999-2000$ & 4 & Ever Married & 10 to 49 & Currently Married & 15 to 59 \\
\hline Bangladesh & $1996-97$ & 3 & Ever Married & 10 to 49 & Currently Married & 15 to 59 \\
\hline Bangladesh & 1993-94 & 3 & Ever Married & 10 to 49 & $\begin{array}{l}\text { Married to Female } \\
\text { Resp. }\end{array}$ & All \\
\hline Benin & 2011-12 & 6 & All & 15 to 49 & All & 15 to 64 \\
\hline Benin & 2006 & 5 & All & 15 to 49 & All & 15 to 64 \\
\hline Benin & 2001 & 4 & All & 15 to 49 & All & 15 to 64 \\
\hline Benin & 1996 & 3 & All & 15 to 49 & All & 20 to 64 \\
\hline Bolivia & 2008 & 5 & All & 15 to 49 & All & 15 to 64 \\
\hline Bolivia & 2003 & 4 & All & 15 to 49 & All & 15 to 64 \\
\hline Bolivia & 1998 & 3 & All & 15 to 49 & All & 15 to 64 \\
\hline Bolivia & 1994 & 3 & All & 15 to 49 & -- & -- \\
\hline Bolivia & 1989 & 1 & All & 15 to 49 & -- & -- \\
\hline Botswana & 1988 & 1 & All & 15 to 49 & -- & -- \\
\hline Brazil & 1996 & 3 & All & 15 to 49 & All & 15 to 59 \\
\hline Brazil & 1991 & 2 & All & 15 to 49 & $\begin{array}{l}\text { Married to Female } \\
\text { Resp. }\end{array}$ & All \\
\hline Brazil & 1986 & 1 & All & 15 to 44 & -- & -- \\
\hline Burkina Faso & 2010 & 6 & All & 15 to 49 & All & 15 to 59 \\
\hline Burkina Faso & 2003 & 4 & All & 15 to 49 & All & 15 to 59 \\
\hline Burkina Faso & 1998-99 & 3 & All & 15 to 49 & All & 15 to 59 \\
\hline Burkina Faso & 1993 & 2 & All & 15 to 49 & All & $18+$ \\
\hline Burundi & 2010 & 6 & All & 15 to 49 & All & 15 to 59 \\
\hline Burundi & 1987 & 1 & All & 15 to 49 & $\begin{array}{l}\text { Married to Female } \\
\text { Resp. }\end{array}$ & All \\
\hline Cambodia & 2014 & 7 & All & 15 to 49 & All & 15 to 49 \\
\hline Cambodia & 2010 & 6 & All & 15 to 49 & All & 15 to 49 \\
\hline Cambodia & 2005 & 5 & All & 15 to 49 & All & 15 to 49 \\
\hline Cambodia & 2000 & 4 & All & 15 to 49 & -- & -- \\
\hline Cameroon & 2011 & 6 & All & 15 to 49 & All & 15 to 59 \\
\hline
\end{tabular}




\begin{tabular}{|c|c|c|c|c|c|c|}
\hline Country & Survey Year & $\begin{array}{l}\text { DHS } \\
\text { Phase }\end{array}$ & $\begin{array}{l}\text { Women's Marital } \\
\text { Status }\end{array}$ & $\begin{array}{l}\text { Women's Age } \\
\text { Range }\end{array}$ & Men's Marital Status & $\begin{array}{l}\text { Men's Age } \\
\text { Range }\end{array}$ \\
\hline Cameroon & 2004 & 4 & All & 15 to 49 & All & 15 to 59 \\
\hline Cameroon & 1998 & 3 & All & 15 to 49 & All & 15 to 59 \\
\hline Cameroon & 1991 & 2 & All & 15 to 49 & -- & -- \\
\hline Cape Verde & 2005 & 4 & All & 15 to 49 & All & 15 to 59 \\
\hline Central African Republic & 1994-95 & 3 & All & 15 to 49 & All & 15 to 59 \\
\hline Chad & 2014-15 & 7 & All & 15 to 49 & All & 15 to 59 \\
\hline Chad & 2004 & 4 & All & 15 to 49 & All & 15 to 59 \\
\hline Chad & $1996-97$ & 3 & All & 15 to 49 & All & 15 to 59 \\
\hline Colombia & 2015 & 7 & All & 13 to 49 & All & 13 to 59 \\
\hline Colombia & 2010 & 6 & All & 13 to 49 & -- & -- \\
\hline Colombia & 2005 & 5 & All & 13 to 49 & -- & -- \\
\hline Colombia & 2000 & 4 & All & 15 to 49 & -- & -- \\
\hline Colombia & 1995 & 3 & All & 15 to 49 & -- & -- \\
\hline Colombia & 1990 & 2 & All & 15 to 49 & -- & -- \\
\hline Colombia & 1986 & 1 & All & 15 to 49 & -- & -- \\
\hline Comoros & 2012 & 6 & All & 15 to 49 & All & 15 to 59 \\
\hline Comoros & 1996 & 3 & All & 15 to 49 & All & 15 to 64 \\
\hline Congo & $2011-12$ & 6 & All & 15 to 49 & All & 15 to 59 \\
\hline Congo & 2005 & 5 & All & 15 to 49 & All & 15 to 59 \\
\hline Congo Dem. Republic & $2013-14$ & 6 & All & 15 to 49 & All & 15 to 59 \\
\hline Congo Dem. Republic & 2007 & 5 & All & 15 to 49 & All & 15 to 59 \\
\hline Cote d'Ivoire & $2011-12$ & 6 & All & 15 to 49 & All & 15 to 59 \\
\hline Cote d'Ivoire & 1998-99 & 3 & All & 15 to 49 & All & 15 to 59 \\
\hline Cote d'Ivoire & 1994 & 3 & All & 15 to 49 & All & 15 to 59 \\
\hline Dominican Republic & 2013 & 6 & All & 15 to 49 & All & 15 to 59 \\
\hline Dominican Republic & 2007 & 5 & All & 15 to 49 & All & 15 to 59 \\
\hline Dominican Republic & 2002 & 4 & All & 15 to 49 & All & 15 to 59 \\
\hline Dominican Republic & 1999 & 4 & All & 15 to 49 & All & 15 to 64 \\
\hline Dominican Republic & 1996 & 3 & All & 15 to 49 & All & 15 to 64 \\
\hline Dominican Republic & 1991 & 2 & All & 15 to 49 & -- & -- \\
\hline Dominican Republic & 1986 & 1 & All & 15 to 49 & -- & -- \\
\hline Ecuador & 1987 & 1 & All & 15 to 49 & -- & -- \\
\hline Egypt & 2014 & 6 & Ever Married & 15 to 49 & -- & -- \\
\hline Egypt & 2008 & 5 & Ever Married & 15 to 49 & -- & -- \\
\hline Egypt & 2005 & 5 & Ever Married & 15 to 49 & -- & -- \\
\hline Egypt & 2000 & 4 & Ever Married & 15 to 49 & -- & -- \\
\hline Egypt & 1995 & 3 & Ever Married & 15 to 49 & -- & -- \\
\hline Egypt & 1992 & 2 & Ever Married & 15 to 49 & $\begin{array}{l}\text { Married to Female } \\
\text { Resp. }\end{array}$ & All \\
\hline Egypt & 1988 & 1 & Ever Married & 15 to 49 & -- & -- \\
\hline El Salvador & 1985 & 1 & All & 15 to 49 & -- & -- \\
\hline Equatorial Guinea & 2011 & 6 & All & 15 to 49 & All & 15 to 59 \\
\hline Eritrea & 2002 & 4 & All & 15 to 49 & -- & -- \\
\hline Eritrea & 1995 & 3 & All & 15 to 49 & All & 15 to 59 \\
\hline Ethiopia & 2011 & 6 & All & 15 to 49 & All & 15 to 59 \\
\hline
\end{tabular}




\begin{tabular}{|c|c|c|c|c|c|c|}
\hline Country & Survey Year & $\begin{array}{l}\text { DHS } \\
\text { Phase } \\
\end{array}$ & $\begin{array}{l}\text { Women's Marital } \\
\text { Status }\end{array}$ & $\begin{array}{l}\text { Women's Age } \\
\text { Range }\end{array}$ & Men's Marital Status & $\begin{array}{l}\text { Men's Age } \\
\text { Range } \\
\end{array}$ \\
\hline Ethiopia & 2005 & 5 & All & 15 to 49 & All & 15 to 59 \\
\hline Ethiopia & 2000 & 4 & All & 15 to 49 & All & 15 to 59 \\
\hline Gabon & 2012 & 6 & All & 15 to 49 & All & 15 to 59 \\
\hline Gabon & 2000 & 4 & All & 15 to 49 & All & 15 to 59 \\
\hline Gambia & 2013 & 6 & All & 15 to 49 & All & 15 to 59 \\
\hline Ghana & 2014 & 7 & All & 15 to 49 & All & 15 to 59 \\
\hline Ghana & 2008 & 5 & All & 15 to 49 & All & 15 to 59 \\
\hline Ghana & 2003 & 4 & All & 15 to 49 & All & 15 to 59 \\
\hline Ghana & 1998 & 4 & All & 15 to 49 & All & 15 to 59 \\
\hline Ghana & 1993 & 3 & All & 15 to 49 & All & 15 to 59 \\
\hline Ghana & 1988 & 1 & All & 15 to 49 & $\begin{array}{l}\text { Married to Female } \\
\text { Resp. }\end{array}$ & All \\
\hline Guatemala & 2014-15 & 7 & All & 15 to 49 & All & 15 to 59 \\
\hline Guatemala & 1995 & 3 & All & 15 to 49 & -- & -- \\
\hline Guatemala & 1987 & 1 & All & 15 to 44 & -- & -- \\
\hline Guinea & 2012 & 6 & All & 15 to 49 & All & 15 to 59 \\
\hline Guinea & 2005 & 5 & All & 15 to 49 & All & 15 to 59 \\
\hline Guinea & 1999 & 4 & All & 15 to 49 & All & 15 to 59 \\
\hline Guyana & 2009 & 5 & All & 15 to 49 & All & 15 to 49 \\
\hline Haiti & 2012 & 6 & All & 15 to 49 & All & 15 to 59 \\
\hline Haiti & 2005-06 & 5 & All & 15 to 49 & All & 15 to 59 \\
\hline Haiti & 2000 & 4 & All & 15 to 49 & All & 15 to 59 \\
\hline Haiti & 1994-95 & 3 & All & 15 to 49 & All & 15 to 59 \\
\hline Honduras & 2011-12 & 6 & All & 15 to 49 & All & 15 to 59 \\
\hline Honduras & 2005-06 & 5 & All & 15 to 49 & -- & -- \\
\hline India & 2005-06 & 5 & All & 15 to 49 & All & 15 to 54 \\
\hline India & $1998-99$ & 4 & Ever Married & 15 to 49 & -- & -- \\
\hline India & $1992-93$ & 2 & Ever Married & 13 to 49 & -- & -- \\
\hline Indonesia & 2012 & 6 & All & 15 to 49 & Ever Married & 15 to 54 \\
\hline Indonesia & 2007 & 5 & Ever Married & 15 to 49 & Currently Married & 15 to 54 \\
\hline Indonesia & $2002-03$ & 4 & Ever Married & 15 to 49 & Currently Married & 15 to 54 \\
\hline Indonesia & 1997 & 3 & Ever Married & 15 to 49 & -- & -- \\
\hline Indonesia & 1994 & 3 & Ever Married & 15 to 49 & -- & -- \\
\hline Indonesia & 1991 & 2 & Ever Married & 15 to 49 & -- & -- \\
\hline Indonesia & 1987 & 1 & Ever Married & 15 to 49 & -- & -- \\
\hline Jordan & 2012 & 6 & Ever Married & 15 to 49 & -- & -- \\
\hline Jordan & 2007 & 5 & Ever Married & 15 to 49 & -- & -- \\
\hline Jordan & 2002 & 4 & Ever Married & 15 to 49 & -- & -- \\
\hline Jordan & 1997 & 3 & Ever Married & 15 to 49 & -- & -- \\
\hline Jordan & 1990 & 2 & Ever Married & 15 to 49 & -- & -- \\
\hline Kazakhstan & 1999 & 4 & All & 15 to 49 & All & 15 to 59 \\
\hline Kazakhstan & 1995 & 3 & All & 15 to 49 & -- & -- \\
\hline Kenya & 2014 & 7 & All & 15 to 49 & All & 15 to 54 \\
\hline Kenya & 2008-09 & 5 & All & 15 to 49 & All & 15 to 54 \\
\hline Kenya & 2003 & 4 & All & 15 to 49 & All & 15 to 54 \\
\hline
\end{tabular}




\begin{tabular}{|c|c|c|c|c|c|c|}
\hline Country & Survey Year & $\begin{array}{l}\text { DHS } \\
\text { Phase } \\
\end{array}$ & $\begin{array}{l}\text { Women's Marital } \\
\text { Status }\end{array}$ & $\begin{array}{l}\text { Women's Age } \\
\text { Range } \\
\end{array}$ & Men's Marital Status & $\begin{array}{l}\text { Men's Age } \\
\text { Range } \\
\end{array}$ \\
\hline Kenya & 1998 & 3 & All & 15 to 49 & All & 15 to 54 \\
\hline Kenya & 1993 & 3 & All & 15 to 49 & All & 20 to 54 \\
\hline Kenya & 1989 & 1 & All & 15 to 49 & $\begin{array}{l}\text { Married to Female } \\
\text { Resp. }\end{array}$ & All \\
\hline Kyrgyz Republic & 2012 & 6 & All & 15 to 49 & All & 15 to 59 \\
\hline Kyrgyz Republic & 1997 & 3 & All & 15 to 49 & -- & -- \\
\hline Lesotho & 2014 & 7 & All & 15 to 49 & All & 15 to 59 \\
\hline Lesotho & 2009 & 6 & All & 15 to 49 & All & 15 to 59 \\
\hline Lesotho & 2004 & 4 & All & 15 to 49 & All & 15 to 59 \\
\hline Liberia & 2013 & 6 & All & 15 to 49 & All & 15 to 49 \\
\hline Liberia & 2007 & 5 & All & 15 to 49 & All & 15 to 49 \\
\hline Liberia & 1986 & 1 & All & 15 to 49 & -- & -- \\
\hline Madagascar & 2008-09 & 5 & All & 15 to 49 & All & 15 to 59 \\
\hline Madagascar & 2003-04 & 4 & All & 15 to 49 & All & 15 to 59 \\
\hline Madagascar & 1997 & 3 & All & 15 to 49 & -- & -- \\
\hline Madagascar & 1992 & 2 & All & 15 to 49 & -- & -- \\
\hline Malawi & $2015-16$ & 7 & All & 15 to 49 & All & 15 to 54 \\
\hline Malawi & 2010 & 6 & All & 15 to 49 & All & 15 to 54 \\
\hline Malawi & 2004 & 4 & All & 15 to 49 & All & 15 to 54 \\
\hline Malawi & 2000 & 4 & All & 15 to 49 & All & 15 to 54 \\
\hline Malawi & 1992 & 2 & All & 15 to 49 & All & 20 to 54 \\
\hline Maldives & 2009 & 5 & Ever Married & 15 to 49 & Ever Married & 15 to 64 \\
\hline Mali & 2012-13 & 6 & All & 15 to 49 & All & 15 to 59 \\
\hline Mali & 2006 & 5 & All & 15 to 49 & All & 15 to 59 \\
\hline Mali & 2001 & 4 & All & 15 to 49 & All & 15 to 59 \\
\hline Mali & 1995-96 & 3 & All & 15 to 49 & All & 15 to 59 \\
\hline Mali & 1987 & 1 & All & 15 to 49 & All & 20 to 55 \\
\hline Mexico & 1987 & 1 & All & 15 to 49 & -- & -- \\
\hline Moldova & 2005 & 5 & All & 15 to 49 & All & 15 to 59 \\
\hline Morocco & 2003-04 & 4 & All & 15 to 49 & -- & -- \\
\hline Morocco & 1992 & 2 & All & 15 to 49 & All & $20+$ \\
\hline Morocco & 1987 & 1 & Ever Married & 15 to 49 & -- & -- \\
\hline Mozambique & 2011 & 6 & All & 15 to 49 & All & 15 to 64 \\
\hline Mozambique & 2003 & 4 & All & 15 to 49 & All & 15 to 64 \\
\hline Mozambique & 1997 & 3 & All & 15 to 49 & All & 15 to 64 \\
\hline Myanmar & 2015-16 & 7 & All & 15 to 49 & All & 15 to 49 \\
\hline Namibia & 2013 & 6 & All & 15 to 49 & All & 15 to 64 \\
\hline Namibia & 2006-07 & 5 & All & 15 to 49 & All & 15 to 49 \\
\hline Namibia & 2000 & 4 & All & 15 to 49 & All & 15 to 59 \\
\hline Namibia & 1992 & 2 & All & 15 to 49 & -- & -- \\
\hline Nepal & 2011 & 6 & All & 15 to 49 & All & 15 to 49 \\
\hline Nepal & 2006 & 5 & All & 15 to 49 & All & 15 to 59 \\
\hline Nepal & 2001 & 4 & Ever Married & 15 to 49 & Ever Married & 15 to 59 \\
\hline Nepal & 1996 & 3 & Ever Married & 15 to 49 & -- & -- \\
\hline Nicaragua & 2001 & 4 & All & 15 to 49 & -- & -- \\
\hline
\end{tabular}




\begin{tabular}{|c|c|c|c|c|c|c|}
\hline Country & Survey Year & $\begin{array}{l}\text { DHS } \\
\text { Phase } \\
\end{array}$ & $\begin{array}{l}\text { Women's Marital } \\
\text { Status }\end{array}$ & $\begin{array}{l}\text { Women's Age } \\
\text { Range }\end{array}$ & Men’s Marital Status & $\begin{array}{l}\text { Men's Age } \\
\text { Range } \\
\end{array}$ \\
\hline Nicaragua & 1998 & 3 & All & 15 to 49 & All & 15 to 59 \\
\hline Niger & 2012 & 6 & All & 15 to 49 & All & 15 to 59 \\
\hline Niger & 2006 & 5 & All & 15 to 49 & All & 15 to 59 \\
\hline Niger & 1998 & 3 & All & 15 to 49 & All & 15 to 59 \\
\hline Niger & 1992 & 2 & All & 15 to 49 & $\begin{array}{l}\text { Married to Female } \\
\text { Resp. }\end{array}$ & All \\
\hline Nigeria & 2013 & 6 & All & 15 to 49 & All & 15 to 49 \\
\hline Nigeria & 2008 & 5 & All & 15 to 49 & All & 15 to 59 \\
\hline Nigeria & 2003 & 4 & All & 15 to 49 & All & 15 to 59 \\
\hline Nigeria & 1999 & 4 & All & 10 to 49 & All & 15 to 64 \\
\hline Nigeria & 1990 & 2 & All & 15 to 49 & -- & -- \\
\hline Pakistan & $2012-13$ & 6 & Ever Married & 15 to 49 & Ever Married & 15 to 49 \\
\hline Pakistan & 2006-07 & 5 & Ever Married & 15 to 49 & -- & -- \\
\hline Pakistan & 1990-91 & 2 & Ever Married & 15 to 49 & $\begin{array}{l}\text { Married to Female } \\
\text { Resp. }\end{array}$ & All \\
\hline Paraguay & 1990 & 2 & All & 15 to 49 & -- & -- \\
\hline Peru & 2000 & 4 & All & 15 to 49 & -- & -- \\
\hline Peru & 1996 & 3 & All & 15 to 49 & All & 15 to 59 \\
\hline Peru & 1991-92 & 2 & All & 15 to 49 & -- & -- \\
\hline Peru & 1986 & 1 & All & 15 to 49 & -- & -- \\
\hline Philippines & 2013 & 6 & All & 15 to 49 & -- & -- \\
\hline Philippines & 2008 & 5 & All & 15 to 49 & -- & -- \\
\hline Philippines & 2003 & 4 & All & 15 to 49 & All & 15 to 54 \\
\hline Philippines & 1998 & 3 & All & 15 to 49 & -- & -- \\
\hline Philippines & 1993 & 3 & All & 15 to 49 & -- & -- \\
\hline Rwanda & 2014-15 & 7 & All & 15 to 49 & All & 15 to 59 \\
\hline Rwanda & 2010 & 6 & All & 15 to 49 & All & 15 to 59 \\
\hline Rwanda & 2005 & 5 & All & 15 to 49 & All & 15 to 59 \\
\hline Rwanda & 2000 & 4 & All & 15 to 49 & All & 15 to 59 \\
\hline Rwanda & 1992 & 2 & All & 15 to 49 & $\begin{array}{l}\text { Married to Female } \\
\text { Resp. }\end{array}$ & All \\
\hline Samoa & 2009 & 5 & All & 15 to 49 & All & 15 to 54 \\
\hline Sao Tome and Principe & 2008-09 & 5 & All & 15 to 49 & All & 15 to 59 \\
\hline Senegal & $2010-11$ & 6 & All & 15 to 49 & All & 15 to 59 \\
\hline Senegal & 2005 & 4 & All & 15 to 49 & All & 15 to 59 \\
\hline Senegal & 1999 & 4 & All & 15 to 49 & All & 15 to 59 \\
\hline Senegal & 1997 & 3 & All & 15 to 49 & All & $20+$ \\
\hline Senegal & $1992-93$ & 2 & All & 15 to 49 & All & $20+$ \\
\hline Senegal & 1986 & 1 & All & 15 to 49 & -- & -- \\
\hline Sierra Leone & 2013 & 6 & All & 15 to 49 & All & 15 to 59 \\
\hline Sierra Leone & 2008 & 5 & All & 15 to 49 & All & 15 to 59 \\
\hline South Africa & 2003 & 4 & All & 15 to 49 & All & 15 to 59 \\
\hline South Africa & 1998 & 3 & All & 15 to 49 & -- & -- \\
\hline Sri Lanka & 2006-07 & 4 & Ever Married & 15 to 49 & -- & -- \\
\hline Sri Lanka & 1987 & 1 & Ever Married & 15 to 49 & -- & -- \\
\hline Sudan & 1989-1990 & 1 & Ever Married & 15 to 49 & -- & -- \\
\hline
\end{tabular}




\begin{tabular}{|c|c|c|c|c|c|c|}
\hline Country & Survey Year & $\begin{array}{l}\text { DHS } \\
\text { Phase }\end{array}$ & $\begin{array}{l}\text { Women's Marital } \\
\text { Status }\end{array}$ & $\begin{array}{l}\text { Women's Age } \\
\text { Range }\end{array}$ & Men's Marital Status & $\begin{array}{l}\text { Men's Age } \\
\text { Range }\end{array}$ \\
\hline Swaziland & 2006-07 & 5 & All & 15 to 49 & All & 15 to 49 \\
\hline Tajikistan & 2012 & 6 & All & 15 to 49 & -- & -- \\
\hline Tanzania & $2015-16$ & 7 & All & 15 to 49 & All & 15 to 59 \\
\hline Tanzania & 2010 & 6 & All & 15 to 49 & All & 15 to 49 \\
\hline Tanzania & 2004-05 & 4 & All & 15 to 49 & All & 15 to 49 \\
\hline Tanzania & 1999 & 4 & All & 15 to 49 & All & 15 to 59 \\
\hline Tanzania & 1996 & 3 & All & 15 to 49 & All & 15 to 59 \\
\hline Tanzania & 1991-92 & 2 & All & 15 to 49 & All & 15 to 60 \\
\hline Thailand & 1987 & 1 & Ever Married & 15 to 49 & -- & -- \\
\hline Timor-Leste & $2009-10$ & 6 & All & 15 to 49 & All & 15 to 49 \\
\hline Togo & 2013-14 & 6 & All & 15 to 49 & All & 15 to 59 \\
\hline Togo & 1998 & 3 & All & 15 to 49 & All & 12 to 59 \\
\hline Togo & 1988 & 1 & All & 15 to 49 & -- & -- \\
\hline Trinidad \& Tobago & 1987 & 1 & All & 15 to 49 & -- & -- \\
\hline Tunisia & 1988 & 1 & Ever Married & 15 to 49 & -- & -- \\
\hline Turkey & 2003 & 4 & Ever Married & 15 to 49 & -- & -- \\
\hline Turkey & 1998 & 4 & Ever Married & 15 to 49 & $\begin{array}{l}\text { Married to Female } \\
\text { Resp. }\end{array}$ & All \\
\hline Turkey & 1993 & 3 & Ever Married & 12 to 49 & -- & -- \\
\hline Turkmenistan & 2000 & 4 & All & 15 to 49 & -- & -- \\
\hline Uganda & 2011 & 6 & All & 15 to 49 & All & 15 to 54 \\
\hline Uganda & 2006 & 5 & All & 15 to 49 & All & 15 to 54 \\
\hline Uganda & 2000-01 & 4 & All & 15 to 49 & All & 15 to 54 \\
\hline Uganda & 1995 & 3 & All & 15 to 49 & All & 15 to 54 \\
\hline Uganda & 1988-89 & 1 & All & 15 to 49 & -- & -- \\
\hline Ukraine & 2007 & 5 & All & 15 to 49 & All & 15 to 49 \\
\hline Uzbekistan & 1996 & 3 & All & 15 to 49 & -- & -- \\
\hline Vietnam & 2002 & 4 & Ever Married & 15 to 49 & -- & -- \\
\hline Vietnam & 1997 & 3 & Ever Married & 15 to 49 & -- & -- \\
\hline Yemen & 2013 & 6 & All & 15 to 49 & -- & -- \\
\hline Yemen & 1997 & 3 & Ever Married & 15 to 49 & -- & -- \\
\hline Yemen & 1991-92 & 2 & Ever Married & 15 to 49 & -- & -- \\
\hline Zambia & 2013-14 & 6 & All & 15 to 49 & All & 15 to 59 \\
\hline Zambia & 2007 & 5 & All & 15 to 49 & All & 15 to 59 \\
\hline Zambia & 2001-02 & 4 & All & 15 to 49 & All & 15 to 59 \\
\hline Zambia & 1996 & 3 & All & 15 to 49 & All & 15 to 59 \\
\hline Zambia & 1992 & 2 & All & 15 to 49 & -- & -- \\
\hline Zimbabwe & 2015 & 7 & All & 15 to 49 & All & 15 to 54 \\
\hline Zimbabwe & $2010-11$ & 6 & All & 15 to 49 & All & 15 to 54 \\
\hline Zimbabwe & 2005-06 & 5 & All & 15 to 49 & All & 15 to 54 \\
\hline Zimbabwe & 1999 & 4 & All & 15 to 49 & All & 15 to 54 \\
\hline Zimbabwe & 1994 & 3 & All & 15 to 49 & All & 15 to 54 \\
\hline Zimbabwe & 1988 & 1 & All & 15 to 49 & -- & -- \\
\hline
\end{tabular}

Notes: Only Standard DHS Phases included; excludes special, MIS, AIS, KAP, continuous, and in-depth surveys 
Table A2. Proportion of men's to women's surveys, DHS for 88 countries, 1985-2015

\begin{tabular}{|c|c|c|c|}
\hline Country & Country Total, Women & Country Total, Men & $\begin{array}{l}\text { Men's surveys as a proportion of } \\
\text { women's }\end{array}$ \\
\hline Afghanistan & 1 & 1 & $100 \%$ \\
\hline Albania & 1 & 1 & $100 \%$ \\
\hline Angola & 1 & 1 & $100 \%$ \\
\hline Armenia & 3 & 3 & $100 \%$ \\
\hline Azerbaijan & 1 & 1 & $100 \%$ \\
\hline Bangladesh & 7 & 5 & $71 \%$ \\
\hline Benin & 4 & 4 & $100 \%$ \\
\hline Bolivia & 5 & 3 & $60 \%$ \\
\hline Botswana & 1 & 0 & $0 \%$ \\
\hline Brazil & 3 & 2 & $67 \%$ \\
\hline Burkina Faso & 4 & 4 & $100 \%$ \\
\hline Burundi & 2 & 2 & $100 \%$ \\
\hline Cambodia & 4 & 3 & $75 \%$ \\
\hline Cameroon & 4 & 3 & $75 \%$ \\
\hline Cape Verde & 1 & 1 & $100 \%$ \\
\hline Central African Rep. & 1 & 1 & $100 \%$ \\
\hline Chad & 3 & 3 & $100 \%$ \\
\hline Colombia & 7 & 1 & $14 \%$ \\
\hline Comoros & 2 & 2 & $100 \%$ \\
\hline Congo & 2 & 2 & $100 \%$ \\
\hline Congo Dem. Republic & 2 & 2 & $100 \%$ \\
\hline Côte d'Ivoire & 3 & 3 & $100 \%$ \\
\hline Dominican Rep. & 7 & 5 & $71 \%$ \\
\hline Ecuador & 1 & 0 & $0 \%$ \\
\hline Egypt & 7 & 1 & $14 \%$ \\
\hline El Salvador & 1 & 0 & $0 \%$ \\
\hline Eq. Guinea & 1 & 1 & $100 \%$ \\
\hline Eritrea & 2 & 1 & $50 \%$ \\
\hline Ethiopia & 3 & 3 & $100 \%$ \\
\hline Gabon & 2 & 2 & $100 \%$ \\
\hline Gambia & 1 & 1 & $100 \%$ \\
\hline Ghana & 6 & 6 & $100 \%$ \\
\hline Guatemala & 3 & 1 & $33 \%$ \\
\hline Guinea & 3 & 3 & $100 \%$ \\
\hline Guyana & 1 & 1 & $100 \%$ \\
\hline Haiti & 4 & 4 & $100 \%$ \\
\hline Honduras & 2 & 1 & $50 \%$ \\
\hline India & 3 & 1 & $33 \%$ \\
\hline Indonesia & 7 & 3 & $43 \%$ \\
\hline Jordan & 5 & 0 & $0 \%$ \\
\hline Kazakhstan & 2 & 1 & $50 \%$ \\
\hline Kenya & 6 & 6 & $100 \%$ \\
\hline Kyrgyzstan & 2 & 1 & $50 \%$ \\
\hline Lesotho & 3 & 3 & $100 \%$ \\
\hline Liberia & 3 & 2 & $67 \%$ \\
\hline
\end{tabular}




\begin{tabular}{|c|c|c|c|}
\hline Country & Country Total, Women & Country Total, Men & $\begin{array}{l}\text { Men's surveys as a proportion of } \\
\text { women's }\end{array}$ \\
\hline Madagascar & 4 & 2 & $50 \%$ \\
\hline Malawi & 5 & 5 & $100 \%$ \\
\hline Maldives & 1 & 1 & $100 \%$ \\
\hline Mali & 5 & 5 & $100 \%$ \\
\hline Mexico & 1 & 0 & $0 \%$ \\
\hline Moldova & 1 & 1 & $100 \%$ \\
\hline Morocco & 3 & 1 & $33 \%$ \\
\hline Mozambique & 3 & 3 & $100 \%$ \\
\hline Myanmar & 1 & 1 & $100 \%$ \\
\hline Namibia & 4 & 3 & $75 \%$ \\
\hline Nepal & 4 & 3 & $75 \%$ \\
\hline Nicaragua & 2 & 1 & $50 \%$ \\
\hline Niger & 4 & 4 & $100 \%$ \\
\hline Nigeria & 5 & 4 & $80 \%$ \\
\hline Pakistan & 3 & 1 & $33 \%$ \\
\hline Paraguay & 1 & 0 & $0 \%$ \\
\hline Peru & 4 & 1 & $25 \%$ \\
\hline Philippines & 5 & 1 & $20 \%$ \\
\hline Rwanda & 5 & 5 & $100 \%$ \\
\hline Samoa & 1 & 1 & $100 \%$ \\
\hline Sao Tome and Principe & 1 & 1 & $100 \%$ \\
\hline Senegal & 6 & 5 & $83 \%$ \\
\hline Sierra Leone & 2 & 2 & $100 \%$ \\
\hline South Africa & 2 & 1 & $50 \%$ \\
\hline Sri Lanka & 2 & 0 & $0 \%$ \\
\hline Sudan & 1 & 0 & $0 \%$ \\
\hline Swaziland & 1 & 1 & $100 \%$ \\
\hline Tajikistan & 1 & 0 & $0 \%$ \\
\hline Tanzania & 6 & 6 & $100 \%$ \\
\hline Thailand & 1 & 0 & $0 \%$ \\
\hline Timor-Leste & 1 & 1 & $100 \%$ \\
\hline Togo & 3 & 2 & $67 \%$ \\
\hline Trinidad and Tobago & 1 & 0 & $0 \%$ \\
\hline Tunisia & 1 & 0 & $0 \%$ \\
\hline Turkey & 3 & 1 & $33 \%$ \\
\hline Turkmenistan & 1 & 0 & $0 \%$ \\
\hline Uganda & 5 & 4 & $80 \%$ \\
\hline Ukraine & 1 & 1 & $100 \%$ \\
\hline Uzbekistan & 1 & 0 & $0 \%$ \\
\hline Vietnam & 2 & 0 & $0 \%$ \\
\hline Yemen & 3 & 0 & $0 \%$ \\
\hline Zambia & 5 & 4 & $80 \%$ \\
\hline Zimbabwe & 6 & 5 & $83 \%$ \\
\hline
\end{tabular}

